\title{
Development and Validation of a Stability- Indicating High Pressure Liquid Chromatography Method for Determination of Prostaglandin E1 and its Degradation Products in sn Intracavernous Formulation
}

\author{
Victoire Vieillard ${ }^{1 *}$, Ghorbel $\mathbf{N}^{1}$, Deffaux $\mathbf{C}^{1}$, Astier $\mathbf{A}^{1}$, Yiou $\mathbf{R}^{2}$ and Paul $\mathbf{M}^{1}$
}

${ }^{1}$ APHP, GH Henri Mondor, Département de Pharmacie, 51 avenue du Maréchal de Lattre de Tassigny, 94010 Créteil, France

${ }^{2}$ APHP, GH Henri Mondor, Service d'Urologie, 51 avenue du Maréchal de Lattre de Tassigny, 94010 Créteil, France

\begin{abstract}
A new intracavernous formulation to overcome the failure of standard treatments of erectile dysfunction after radical prostatectomy was developed. This formulation contains prostaglandin E1 (pGE1) at $15 \mu \mathrm{g} / \mathrm{ml}$ in association with papaverin and urapidil at $15 \mathrm{mg} / \mathrm{ml}$ and $2.5 \mathrm{mg} / \mathrm{ml}$ respectively. Since pGE1 was the main compound to be subject to physico-chemical degradation, its degradation and the concomitant apparition of its degradation product prostaglandin A1 (pGA1) are correlated to the stability of the formulation. The low specific absorbance of PGE1 in the ultraviolet region, and the presence of high levels of papaverin and urapidil in the formulation were the principal difficulties to develop a new method for simultaneous determination of pGE1 and pGA1. Many compositions and pH of mobile phase were studied to find the best chromatographic conditions, and the chosen method is a sensitive, precise and accurate ramp reversed-phase high-performance liquid chromatographic (RP-HPLC) assay method. Ramp RP-HPLC separation was achieved on a Kromasil 5 C18 column $(250 \times 4.6 \mathrm{~mm}$ id, $5 \mu \mathrm{m}$ particle size) using mobile phase composed of acetonitrile-pH 3 phosphate buffer $(37: 63 \%$, v/v). The detection was performed at 205 and $230 \mathrm{~nm}$ for PGE1 and pGA1 respectively, using a multiwave UV detector. The method was validated for specificity, linearity, precision, accuracy, robustness and sensibility. Limits of quantitation were about $3 \mu \mathrm{g} / \mathrm{ml}$ for pGE1 and $0.5 \mu \mathrm{g} / \mathrm{ml}$ for pGA1. The presence of urapidil and papaverin at high concentration did not interfere with determination of pGE1 and pGA1 in the formulation. The method developed which separates all the most degradation products formed under variety of conditions was sensitive, selective, linear, precise and accurate, and thus can be used to study the stability of the formulation.
\end{abstract}

Keywords: Formulation; Validation; Chromatography

\section{Introduction}

Erectile dysfunction is a well-known complication induced by abdominal and pelvic surgery. Radical treatment of a malignancy, vascular operations and transurethral resection can lead to the rise of these disorders. Some of the main common methods of management are penile implants, oral phosphodiesterase (PDE) inhibitors, vacuum devices, intraurethral prostaglandins $(\mathrm{PG})$ and intracavernous injection of PG, papaverin or phentolamin [1-4]. Actual treatments of erectile dysfunction after prostatectomy are not completely efficient; some patients don't respond or don't tolerate intracavernous injection of high concentrations of PGE1 in monotherapy or in association with oral PDE inhibitors when they are not contra-indicated, thus leading to the development of "vasoactive cocktails" in intracavernous injection [5-7].

Most vasoactive cocktails reviewed in literature are also called "trimix" and are composed of PGE1, papaverin and phentolamin at variable concentrations $[8,9]$.

Since phentolamin is not commercialized in France, it has been replaced by urapidil, an another $\alpha$-bloker.

The formulation studied in this work contains PGE1 at $15 \mu \mathrm{g} / \mathrm{ml}$ in association with papaverin and urapidil at $15 \mathrm{mg} / \mathrm{ml}$ and $2 \mathrm{mg} / \mathrm{ml}$ respectively; it was prepared from injectable commercial solutions of the different active substances and conditioned in syringes of $1 \mathrm{ml}$.

Since PGE1 is the main constituent subject to undergo physicochemical degradation $[2,10]$, following its degradation and concomitant apparition of its degradation product PGA1 enables to evaluate the stability of the formulation [11].
To study the stability of this mixture, it is necessary to have analytical methods allowing the separation of the numerous products and in particular which can measure PGE1, which has a low UV absorption. Various HPLC methods have already been described in the literature for determination of PGE1 by HPLC [12-15] but they are not used for determination in Trimix.

The aim of this work was to develop and validate according to the ICH description, a stability indicating RP-HPLC method that allows a simultaneous determination of PGE1 and its degradation product PGA1 in presence of urapidil and papaverin.

\section{Experimental}

\section{Materials}

All reagents used were of analytical grade. PGE1, PGA1, papaverin chlorhydrate, urapidil chlorhydrate and acetonitrile were purchased from Sigma Aldrich, absolute ethanol used for the dissolution of

*Corresponding author: Victoire Vieillard, Département de Pharmacie, GH H. Mondor, 51 avenue du Maréchal de Lattre de Tassigny, 94010 Créteil, France, E-mail: victoire.vieillard@hmn.aphp.fr

Received January 10, 2013; Accepted April 20, 2013; Published April 25, 2013

Citation: Vieillard V, Ghorbel N, Deffaux C, Astier A, Yiou R, et al. (2013) Development and Validation of a Stability- Indicating High Pressure Liquid Chromatography Method for Determination of Prostaglandin E1 and its Degradation Products in sn Intracavernous Formulation. Pharmaceut Anal Acta 4 230. doi:10.4172/2153-2435.1000230

Copyright: ( $) 2013$ Vieillard V, et al. This is an open-access article distributed unde the terms of the Creative Commons Attribution License, which permits unrestricted use, distribution, and reproduction in any medium, provided the original author and source are credited. 
Citation: Vieillard V, Ghorbel N, Deffaux C, Astier A, Yiou R, et al. (2013) Development and Validation of a Stability- Indicating High Pressure Liquid Chromatography Method for Determination of Prostaglandin E1 and its Degradation Products in sn Intracavernous Formulation. Pharmaceut Anal Acta 4: 230. doi:10.4172/2153-2435.1000230

Page 2 of 6

prostaglandins was from VWR Prolabo, $\mathrm{KH}_{2} \mathrm{PO}_{4}$ and orthophosphoric acid were from Merk and water was from Versylene.

Prostine $\mathrm{VR}^{\bullet}$ (Alprostadyl $0.5 \mathrm{mg} / \mathrm{ml}$ injectable solution) from Pfizer, Papavérine $\mathrm{SRB}^{\circledast}$ (papaverin $40 \mathrm{mg} / \mathrm{ml}$ injectable solution) from SRB laboratories and Eupressyl ${ }^{\bullet}$ (urapidil $5 \mathrm{mg} / \mathrm{ml}$ injectable solution) from NYCOMED were used to prepare Trimix formulation.

\section{Instrumentation}

The development and validation work were carried out on a chromatographic system consisting of a Dionex Ultimate 3000 system, equipped with a variable wavelength UV-Vis detector model, a quaternary gradient pump equipped with a solvent programmer and a rheodyne model injector with a $100 \mu \mathrm{l}$ sample loop. $\mathrm{pH}$ values were measured with a Consort P901 pH meter using a Fisher scientific $\mathrm{pH}$ glass electrode.

\section{Prepared solutions}

Stock standard solutions: For the preparation of the stock solutions, $1 \mathrm{mg}$ of PGE1 and PGA1 were diluted with $2 \mathrm{ml}$ of absolute ethanol leading to initial solutions of PGE1 and PGA1 of $500 \mu \mathrm{g} / \mathrm{ml}$. Vials of these solutions were stored at $-20^{\circ} \mathrm{C}$ for 3 months.

Working standard solutions: Working solutions were prepared from stock solutions by diluting an adequate volume in $\mathrm{NaCl} 0.9 \%$. Final concentrations were $100 \mu \mathrm{g} / \mathrm{ml}$ and $10 \mu \mathrm{g} / \mathrm{ml}$ for PGE1 and PGA1 respectively. These solutions were not kept after use.

A blank solution was prepared from the injectable solutions of Papavérine SRB ${ }^{\circ} 40 \mathrm{mg} / \mathrm{ml}$ and Eupressyl ${ }^{\circledR} 50 \mathrm{mg} / 10 \mathrm{ml}$. Concentrations of papaverin and urapidil in the blank were the same that in the final formulation.

In a second time, to reconstitute the solution, adequate volumes of work solution of PGE1 were added into the blank solution.

Stock solution of PGE1 $(500 \mu \mathrm{g} / \mathrm{ml})$ was diluted to obtain a working standard solution $(100 \mu \mathrm{g} / \mathrm{ml})$. Five calibration solutions over the range of the theoretical concentration $(15 \mu \mathrm{g} / \mathrm{ml})$ were prepared from this working solution, their concentrations were $12 ; 13.5 ; 15 ; 16.5$ and 18 $\mu \mathrm{g} / \mathrm{ml}$ corresponding to $80 ; 90 ; 100 ; 110$ and $120 \%$ respectively of the nominal concentration of PGE1.

Stock solution of PGA1 $(500 \mu \mathrm{g} / \mathrm{ml})$ was diluted to obtain a standard work solution $(10 \mu \mathrm{g} / \mathrm{ml})$. Five calibration solutions were prepared from this working solution, their concentrations were $356.25 \mathrm{ng} / \mathrm{ml}$; $712.5 \mathrm{ng} / \mathrm{ml} ; 1.425 \mu \mathrm{g} / \mathrm{ml} ; 2.85 \mu \mathrm{g} / \mathrm{ml}$ and $4.275 \mu \mathrm{g} / \mathrm{ml}$ corresponding to $2.5 ; 5 ; 10 ; 20$ and $40 \%$ of PGE1 degradation respectively, i.e. 25; 50; $100 ; 200$; and $400 \%$ of the concentration limit of PGA1 tolerated in the formulation.

Validation standard solutions of PGE1 and PGA1 were prepared in the following way: adequate volumes of working solution of PGE1 (100 $\mu \mathrm{g} / \mathrm{ml}$ ) were added in synthetic mixture of all other components to obtain the same concentrations of PGE1 as in the calibration standard solutions.

Adequate volumes of working solution of PGA1 $(10 \mu \mathrm{g} / \mathrm{ml})$ were added in synthetic mixture of all other components to obtain the same concentrations of PGA1 as in the calibration standard solutions.

\section{Chromatographic conditions}

The separation was performed on a Kromasil C18 column $(250 \times 4.6$ $\mathrm{mm} ; 5 \mu \mathrm{m}$ particles) with a $(63: 37 \mathrm{v} / \mathrm{v})$ mixture of phosphate buffer
$\left(\mathrm{KH}_{2} \mathrm{PO}_{4} 0.02 \mathrm{M}, \mathrm{pH} 3\right)$ and acetonitrile as mobile phase. The injection volume was $100 \mu$ l. The column was thermostated at $25^{\circ} \mathrm{C}$. The mobile phase flow rate was variable: $0-15 \mathrm{~min}$ and $25-40 \mathrm{~min}: 1 \mathrm{ml} / \mathrm{min}$; $15-25$ min: $1.5 \mathrm{ml} / \mathrm{min}$. Several detection wavelengths were used $(205 \mathrm{~nm}$, $230 \mathrm{~nm}$ and $280 \mathrm{~nm}$ ) for detection of PGE1, PGA1 and PGB1, which is a secondary degradation product of PGE1.

\section{Procedures for the method validation}

Validation criteria were the specificity, precision, linearity, concentration range, accuracy and quantification limit.

Specificity: Specificity was demonstrated by examining potential interferences between formulation components, PGE1 and its degradation product PGA1, Papaverin and Urapidil. Specificity was established through study of resolution factors of the drug peak from the nearest resolving peak.

Precision: Six injections of the theoretical concentration of 15 $\mu \mathrm{g} / \mathrm{ml}$ for PGE1 and $1.425 \mu \mathrm{g} / \mathrm{ml}$ for PGA1 (corresponding to $10 \%$ degradation of PGE1) were performed on the same day and relative standard deviation (RSD) was calculated to determine repeatability or intra-day precision. This assay was repeated for 2 days in order to determine intermediate precision or inter-day precision.

Linearity and range: Linearity was determined by injecting calibration standard solutions $(\mathrm{n}=5)$ and standard validation solutions $(\mathrm{n}=5)$ for three days.

Accuracy: The study of accuracy was coupled to the linearity by calculating the recovery between theoretical concentrations of validation standard solutions and those found using calibration curve obtained from calibration standard solutions.

Limit of detection (LOD) and limit of quantitation: LOD and LOQ were calculated experimentally. LOD was defined as the concentration that yields a signal to noise ratio of 3 .

The limit of quantitation was calculated to be the lowest concentration that could be measure with a signal to noise ratio of 10 .

Degradation studies: Forced degradation studies were performed on the stock solution of PGE1 to establish its inherent stability characteristics in order to demonstrate selectivity and stability indicating capability of the proposed method. The standard substances were exposed to:

- Acidic $(0.1 \mathrm{~N} \mathrm{HCl}$, room temperature, 3 hours $)$,-Alkaline $(0.1 \mathrm{~N}$ $\mathrm{NaOH}$, room temperature, 3 hours), -Strong oxidizing ( $3 \%$ $\left.\mathrm{H}_{2} \mathrm{O}_{2}, 80^{\circ} \mathrm{C}, 1 \mathrm{~h}\right)$

- - Thermal degradation conditions $\left(80^{\circ} \mathrm{C}, 1\right.$ day)

All the exposed samples were then analyzed by the proposed method.

\section{Results and Discussion}

\section{HPLC method development and optimization}

The low specific absorbance in the UV zone of PGE1 and the presence of high levels of papaverin and urapidil in the formulation are the principal difficulties to develop a HPLC-UV method for simultaneous determination of PGE1 and PGA1.

Although PGE1 presents a low specific absorbance in the UV zone, UV detection mode was preferred to other detection modes cited in 
Citation: Vieillard V, Ghorbel N, Deffaux C, Astier A, Yiou R, et al. (2013) Development and Validation of a Stability- Indicating High Pressure Liquid Chromatography Method for Determination of Prostaglandin E1 and its Degradation Products in sn Intracavernous Formulation. Pharmaceut Anal Acta 4: 230. doi:10.4172/2153-2435.1000230

literature due to its precision and accuracy, the lack of specificity was compensated by a good chromatographic separation.

The high levels of papaverin and urapidil in the preparation engendered very wide peaks saturating the detector, the resolution of PGE1 and PGA1 depended largely on the wideness of papaverinurapidil peak. The chromatographic conditions were optimized in order to achieve good resolution, symmetrical peak shapes and short analysis time.

Selection of wavelength: The UV detector used allows setting four different wavelengths at the same time, wavelengths selected were 205 $\mathrm{nm}$ for detection of PGE1 and $230 \mathrm{~nm}$ for detection of PGA1. PGA1 and PGB1 have similar chromatographic properties; they will be eluted at the same time. On the other hand, they have very different spectral properties so we chose a third wavelength for detection of PGB1, 278 nm.

Development of the optimum mobile phase: The choice of composition and $\mathrm{pH}$ of mobile phase represents an important point during the development of the chromatographic methods. The chosen organic solvent was acetonitrile because its cut-off $(190 \mathrm{~nm})$ is compatible with detection at $205 \mathrm{~nm}$, different proportions of acetonitrile and phosphate buffer $\left(\mathrm{KH}_{2} \mathrm{PO}_{4} 0.02 \mathrm{M}\right)$ at different $\mathrm{pH}$ have been tested, only a $\mathrm{pH}$ under 3,5 and a proportion of acetonitrile under $40 \%$ allowed a good resolution between the peaks of papaverin and urapidil which were co-eluted and the peak of PGE1. The proportion of
$37 \%$ acetonitrile at $\mathrm{pH} 3$ lead to a good separation of urapidil-papaverin and PGE1 and the "shortest" retention time possible for PGA1, which was about $39 \mathrm{~min}$.

Optimisation of flow rate: In order to shorten retention time of PGA1, a ramp of flow rate has been used: from 0 to $15 \mathrm{~min}$ and from 25 to $40 \mathrm{~min}$ the flow rate was $1 \mathrm{ml} / \mathrm{min}$ and from 15 to $25 \mathrm{~min}$ it was $1.5 \mathrm{ml} / \mathrm{min}$.

Within these conditions, retention time of PGE1 and PGA1 were about $11 \mathrm{~min}$ and $29 \mathrm{~min}$ respectively (Figure 1).

\section{Method validation}

Specificity: The method was specific enough to have a good separation between PGE1 and PGA1 from one hand (Figure 2) and between PGE1 and high concentrations of urapidil and papaverin in the other hand (Figure 3).

The good separation between the peak of PGE1, the peak of PGA1 and the other compounds of the formulation confers a good specificity to the method.

Precision: The \%RSD values for intra-day precision and intermediate precision were $<2 \%(1.188 \%$ and $1.139 \%$ for intra-day precision and $0.608 \%$ and $0.744 \%$ for intermediate precision for PGE1 and PGA1 respectively), which confirms that the method is sufficiently precise (Tables 1 and 2).

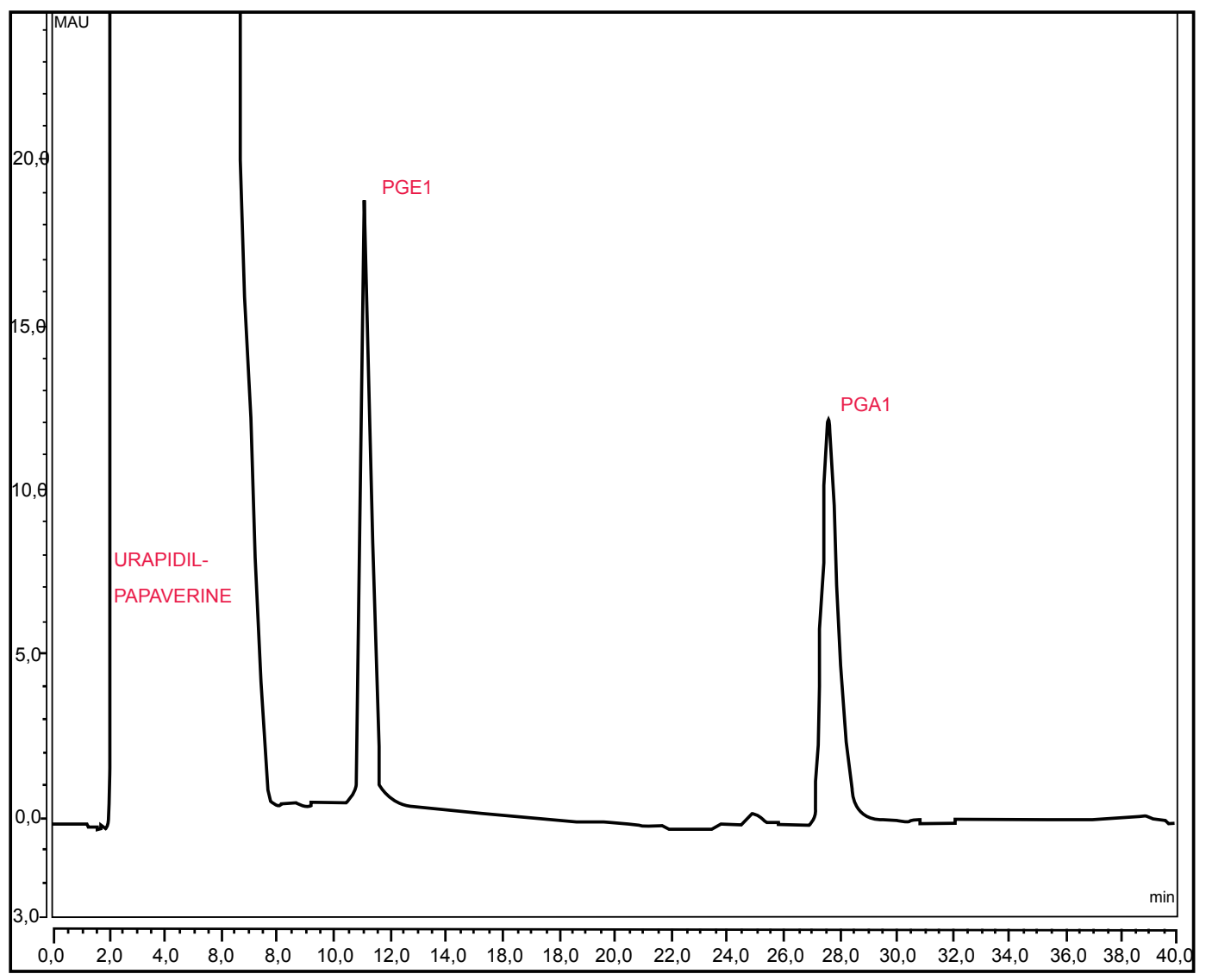

Figure 1: Chromatogram of PGE1 and PGA1 in the formulation. We observed a satisfactory separation by using mixture of phosphate buffer $\left(\mathrm{KH}_{2} \mathrm{PO} \mathrm{O}_{4} 0.02 \mathrm{M}\right.$ acetonitrile in the ratio of $(63: 37 \mathrm{v} / \mathrm{v}) \mathrm{pH} 3$ as a mobile phase and with a ramp of flow rate from $1 \mathrm{ml} / \mathrm{min}$ to $1.5 \mathrm{ml} / \mathrm{min}$. Within these conditions, retention time of $\mathrm{PGE} 1$ and PGA1 were about $11 \mathrm{~min}$ and $29 \mathrm{~min}$. 
Citation: Vieillard V, Ghorbel N, Deffaux C, Astier A, Yiou R, et al. (2013) Development and Validation of a Stability- Indicating High Pressure Liquid Chromatography Method for Determination of Prostaglandin E1 and its Degradation Products in sn Intracavernous Formulation. Pharmaceut Anal Acta 4: 230. doi:10.4172/2153-2435.1000230

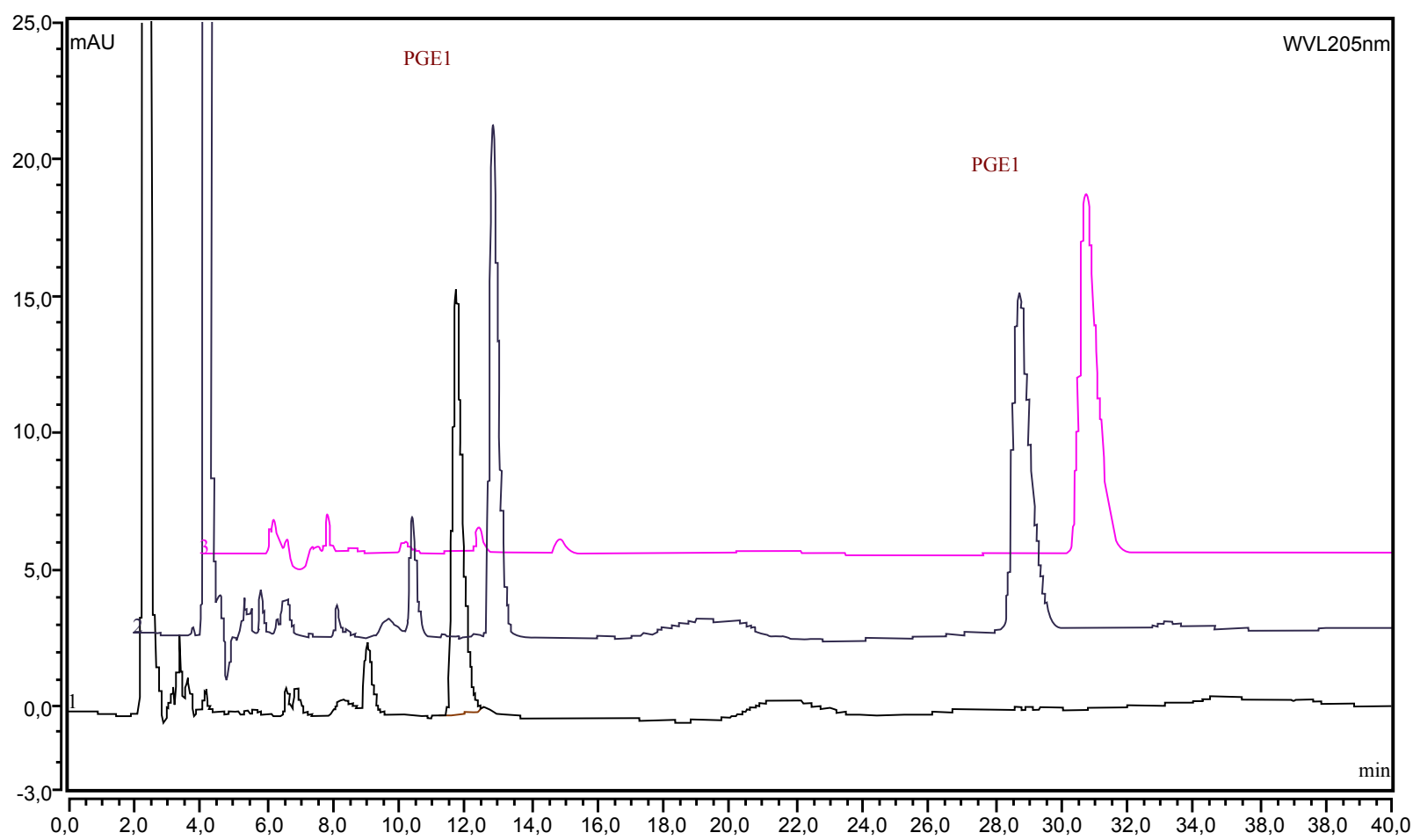

Figure 2: Selectivity of the method is evident from the chromatograms. The black chromatogram was obtained with the solution 1 (PGE1 at $15 \mu \mathrm{g} / \mathrm{ml}$ ); the pink chromatogram was obtained with the solution 2 (PGA1 at $7.125 \mu \mathrm{g} / \mathrm{ml}$ ) and the blue chromatogram was obtained with the solution 3 (mixture of solution of PGE1 at 15 $\mu \mathrm{g} / \mathrm{ml}$ and PGA1 at $7.125 \mu \mathrm{g} / \mathrm{ml})$.

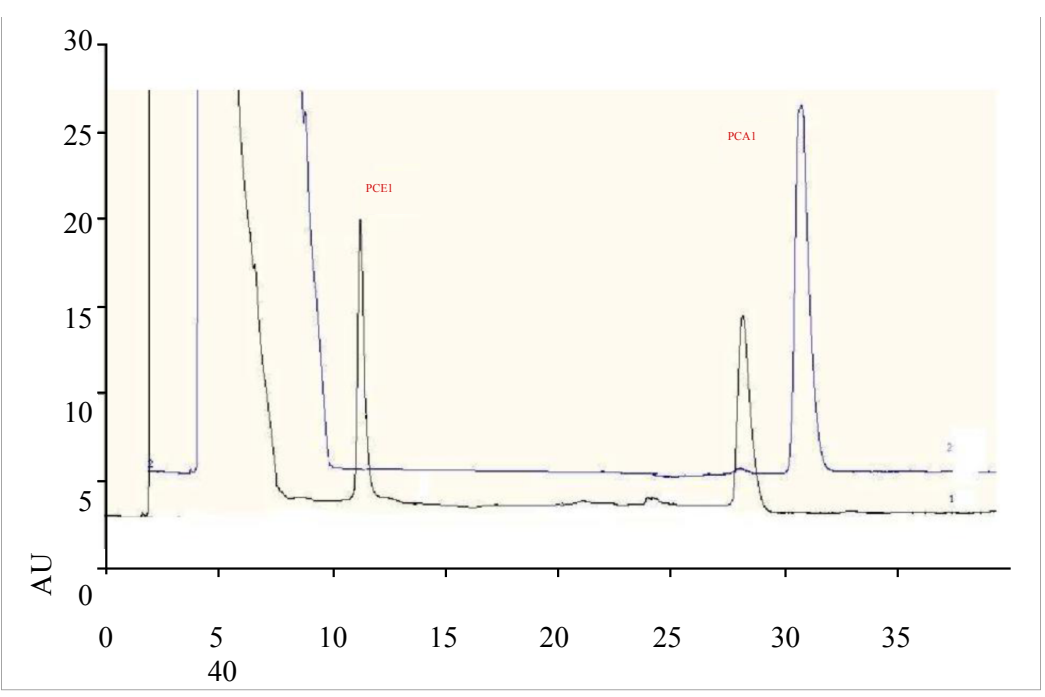

T (min)

Figure 3: Study of the selectivity of the method: Mobile phase: $(63: 37 \mathrm{v} / \mathrm{v})$ mixture of phosphate buffer $\left(\mathrm{KH}_{2} \mathrm{PO}_{4} 0.02 \mathrm{M} \mathrm{pH} 3\right)$ and acetonitrile. Black chromatogram for a detection at $205 \mathrm{~nm}$ and blue chromatogram for a detection at $230 \mathrm{~nm}$.

Linearity: A good linear relationship was obtained between concentration and peak area for both PGE1 and PGA1, showing that the method is linear with a correlation coefficient greater than $99 \%$ (99.77\% and 99.99\% for PGE1 and PGA1 respectively).

Accuracy: Percentages of recovery were calculated from differences between theoretical concentrations and those calculated using calibration curve. As shown from data in tables 3 and 4 , excellent recoveries were found for both PGE1 and PGA1 with CI95\% ranging between $[0.9958 ; 1.0053]$ and $[0.9879 ; 1.0090]$ respectively.

Limit of detection (LOD) and limit of quantitation (LOQ): LOD calculated was $94,43 \mathrm{ng} / \mathrm{ml}$. LOQ calculated was $314 \mathrm{ng} / \mathrm{ml}$. This value is much lower than $356 \mathrm{ng} / \mathrm{ml}$, lower concentration (was) tested 
Citation: Vieillard V, Ghorbel N, Deffaux C, Astier A, Yiou R, et al. (2013) Development and Validation of a Stability- Indicating High Pressure Liquid Chromatography Method for Determination of Prostaglandin E1 and its Degradation Products in sn Intracavernous Formulation. Pharmaceut Anal Acta 4: 230. doi:10.4172/2153-2435.1000230

during the validation of the method. The limit of quantification of PGA1 retained for the method is $356 \mathrm{ng} / \mathrm{ml}$. At this concentration, it was possible to measure pGA1 by the method with accuracy.

Degradation studies: The resulting chromatogram of PGE1 and its major degradation products obtained under stressed conditions is shown in figure 4 . Our results are in accordance with previously studies which described degradation of PGE1 [10]. Degradation of PGE1 was observed under acid as well as alkaline conditions but the degradation

\begin{tabular}{|c|c|c|}
\hline PGE1 & $\begin{array}{c}\text { Actual } \\
\text { concentration } \\
(\boldsymbol{\mu g} / \mathbf{m l})\end{array}$ & AUC (mAU*min) \\
\hline 1 & 15 & 5.5266 \\
\hline 2 & 15 & 5.6385 \\
\hline 3 & 15 & 5.6479 \\
\hline 4 & 15 & 5.6404 \\
\hline 5 & 15 & 5.6941 \\
\hline 6 & 15 & 5.5383 \\
\hline Average & & 5.6143 \\
\hline S.D & & 0.067 \\
\hline R.S.D & & 1.188 \\
\hline
\end{tabular}

Table 1: Intra-day precision of PGE1 quantitation.

\begin{tabular}{|c|c|c|}
\hline PGA1 & $\begin{array}{c}\text { Actual } \\
\text { concentration } \\
(\boldsymbol{\mu} \mathbf{g} / \mathbf{m l})\end{array}$ & AUC $\left(\mathbf{m A U ^ { * } \mathbf { m i n } )}\right.$ \\
\hline 1 & 1.425 & 1.7328 \\
\hline 2 & 1.425 & 1.7466 \\
\hline 3 & 1.425 & 1.7362 \\
\hline 4 & 1.425 & 1.7600 \\
\hline 5 & 1.425 & 1.7396 \\
\hline 6 & 1.425 & 1.7008 \\
\hline Average & & 1.7360 \\
\hline S.D & & 0.020 \\
\hline R.S.D & & 1.139 \\
\hline
\end{tabular}

S.D = Standard Deviation

R.S.D = Relative Standard Deviation

Table 2: Intra-day precision of PGA1 quantitation.

\begin{tabular}{|c|c|c|}
\hline $\begin{array}{c}\text { Theoretical } \\
\text { concentration } \\
\text { PGE1 }(\boldsymbol{\mu g} / \mathbf{m l})\end{array}$ & $\begin{array}{c}\text { Calculated } \\
\text { concentration } \\
(\boldsymbol{\mu g} / \mathbf{m l}) \mathbf{\pm} \text { SD }\end{array}$ & Recovery \\
\hline 12 & $11.976 \pm 0.081$ & 99.8 \\
\hline 13.5 & $13.495 \pm 0.072$ & 99.96 \\
\hline 15 & $15.050 \pm 0.092$ & 100.33 \\
\hline 16.5 & $16.531 \pm 0.155$ & 100.19 \\
\hline 18 & $17.976 \pm 0.086$ & 99.86 \\
\hline
\end{tabular}

S.D = Standard Deviation

Table 3: \% of recoveries for PGE1.

\begin{tabular}{|c|c|c|}
\hline $\begin{array}{l}\text { Theoretical } \\
\text { concentration } \\
\text { PGA1 ( } \mu \mathrm{g} / \mathrm{ml})\end{array}$ & $\begin{array}{c}\text { Calculated } \\
\text { concentration } \\
(\mu \mathrm{g} / \mathrm{ml}) \pm \mathrm{SD}\end{array}$ & Recovery \\
\hline 0.35625 & $0.354 \pm 0.017$ & 99.37 \\
\hline 0.7125 & $0.713 \pm 0.010$ & 100.07 \\
\hline 1.425 & $1.426 \pm 0.005$ & 100.07 \\
\hline 2.85 & $2.848 \pm 0.029$ & 99.93 \\
\hline 4.275 & $4.271 \pm 0.010$ & 99.91 \\
\hline
\end{tabular}

S.D = Standard Deviation

Table 4: \% of recoveries for PGA1.

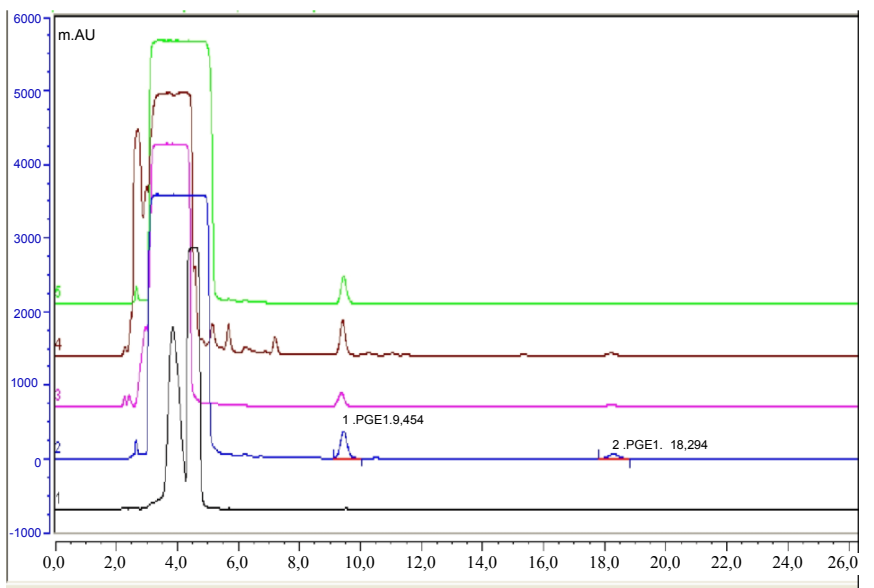

Figure 4: Degradation Studies: resolution was optimized to separate major degradation products. Resolution was checked for all stress condition tested. The resulting chromatogram with degradation products obtained under stressed conditions is shown in this figure. Chromatogram 1 (black): $\mathrm{NaOH} 0.1 \mathrm{~N} 24$ hours, Chromatogram 2 (blue): $80^{\circ} \mathrm{C} 24$ hours, Chromatogram 3 (pink): $\mathrm{HCl} 0.1 \mathrm{~N} 24$ hours, Chromatogram 4 (brown): $\mathrm{H}_{2} \mathrm{O}_{2} 3 \% 24$ hours, Chromatogram 5 (green): T0.

of PGE1 was strongly accelerated with the increase of $\mathrm{pH}$. We also observed degradation of PGE1 and increase of PGA1 in oxidative conditions and in thermal conditions. It indicates that the method is optimized to separate PGE1 and its major degradation products (PGA1) formed under various conditions.

\section{Conclusion}

This work shows the development and the validation of a simple, precise and significant analytical method for determination of PGE1; this method was established following the recommendations of $\mathrm{ICH}$ guidelines. The main difficulty of this development was the low UV absorption of the product, which was also in small quantity in the mixture.

The developed method was sufficiently specific to the PGE1. This assay method showed that it was possible to separate the drug and its degradation products formed under a variety of stress conditions.

This method proved to be simple, accurate, precise, selective and specific. Thus the method developed will be successfully applied for the analysis of Prostaglandin E1 in the vasoactive cocktail.

\section{References}

1. Alexandre B, Lemaire A, Desvaux P, Amar E (2007) Intracavernous injections of prostaglandin $\mathrm{E} 1$ for erectile dysfunction: patient satisfaction and quality of sex life on long-term treatment. J Sex Med 4: 426-431.

2. Lee S, Lee J, Choi YW (2008) Design and evaluation of prostaglandin E1 (PGE1) intraurethral liquid formulation employing self-microemulsifying drug delivery system (SMEDDS) for erectile dysfunction treatment. Biol Phar Bu I 31: 668-672.

3. Urciuoli R, Cantisani TA, Carlinil M, Giuglietti M, Botti FM (2004) Prostaglandin E1 for treatment of erectile dysfunction. Cochrane Database Syst Rev CD001784.

4. Chew KK, Stuckey BGA (2003) Clinical course of penile fibrosis in intracavernosal prostaglandin E1 injection therapy: a follow-up of 44 patients. Int. J Impot Res 15: 94-98.

5. Shah PJ, Dinsmore W, Oakes RA, Hackett G (2007) Injection therapy for the treatment of erectile dysfunction: a comparison between alprostadil and a combination of vasoactive intestinal polypeptide and phentolamine mesilate. Curr Med Res Opin 23: 2577-2583. 
Citation: Vieillard V, Ghorbel N, Deffaux C, Astier A, Yiou R, et al. (2013) Development and Validation of a Stability- Indicating High Pressure Liquid Chromatography Method for Determination of Prostaglandin E1 and its Degradation Products in sn Intracavernous Formulation. Pharmaceut Anal Acta 4: 230. doi:10.4172/2153-2435.1000230

6. Nandipati K, Raina R, Agarwal A, Zippe CD (2006) Early combination therapy: intracavernosal injections and sildenafil following radical prostatectomy increases sexual activity and the return of natural erections. Int J Impot Res 18: $446-451$.

7. Moemen MN, Hamed HA, Kamel II, Shamloul RM, Ghanem HM (2004) Clinical and sonographic assessment of the side effects of intracavernous injection of vasoactive substances. Int J Impot Res 16: 143-145.

8. Ribé N, Rajmil O, Bassas L, Jurado C, Pomerol JM (2001) [Response to intracavernous administration of 3 different drugs in the same group of patients with erectile dysfunction]. Arch Esp Urol 54: 355-359.

9. Kim SC, Seo KK, Lee SK, Song ES, Lee MY (1999) Comparison of the synergistic effects of tamsulosin versus phentolamine on penile erection: in vitro and in vivo studies. Urol Res 27: 437-444.

10. Paul M, Razzouq N, Tixier G, Astier A (2005) Stability of prostaglandin E1 (PGE1) in aqueous solutions. The European Journal of Hospital Pharmacy Science 11: 31-36.
11. Soli M, Bertaccini A, Carparelli F, Gotti R, Cavrini V, et al. (1998) Vasoactive cocktails for erectile dysfunction: chemical stability of PGE1, papaverine and phentolamine. J Urol 16: 551-555.

12. Lee KC, DeLuca PP (1991) Simultaneous determination of prostaglandins E1, $A 1$, and $B 1$ by reversed-phase high-performance liquid chromatography for the kinetic studies of prostaglandin E1 in solution. J Chromatogr 555: 73-80.

13. Hesse WH, Schweer H, Seyberth HW, Peskar BA (1990) Separation and determination of prostaglandin E1 metabolites by high-performance liquid chromatography. J Chromatogr 533: 159-165

14. Zoutendam PH, Bowman PB, Rumph JL, Ryan TM (1984) Quantitative determination of prostaglandins $A 1$ and $B 1$ in alprostadil (PGE1) by highperformance liquid chromatography. J Chromatogr 283: 281-287.

15. Zoutendam PH, Bowman PB, Ryan TM, Rumph JL (1984) Quantitative determination of alprostadil (PGE) in bulk drug and pharmaceutical formulations by high-performance liquid chromatography. J Chromatogr 283: 273-280. 